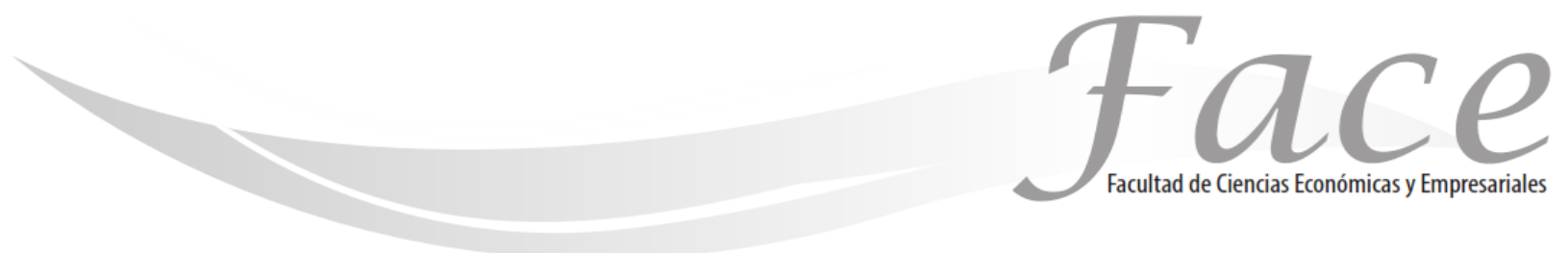

ISSN Impreso: 1794-9920

ISSN Electrónico: 2500-9338

Volumen 16-N¹

Año 2016

Págs. 103 - 113

\title{
MINERÍA RURAL EN COLOMBIA: EL PARAÍSO DE LA LEGALIDAD Y LA ILEGALIDAD
}

\author{
Margarita María Pérez Osorno * \\ Enlace ORCID: http://orcid.org/0000-0002-7178-9702 \\ Angie Betancur Vargas ** \\ Enlace ORCID: http://orcid.org/0000-0002-7662-5408
}

Fecha de Recepción: 12 de Mayo 2016

Fecha de Aprobación: 29 de Julio 2016

\section{Resumen:}

La expansión de la industria minera en Colombia, se ha llevado a cabo en el marco de sus entornos rurales, los cuales son altamente propicios para la ejecución de dicha labor debido a sus características en cuanto a distanciamiento de la sociedad civil y riqueza natural, situación que ha desencadenado un conjunto de modificaciones en cuanto al dinamismo social, cultural y territorial de este tipo de zonas debido a las modificaciones "impuestas" en la mayoría de los casos no solo por parte del Estado por medio de la titulación de áreas mineras, sino también de parte de actores armados al margen de la ley, quienes a su vez, han visto esta actividad una opción rentable y beneficiosa en cuanto al recaudo de ingresos para su sostenimiento. El presente documento, pretende relacionar la incursión de la industria minera con la expansión de los grupos armados al margen de la ley en territorios rurales; lográndose a través de una revisión literaria, de carácter reflexivo y analítico. Teniendo como principal resultado el desplazamiento forzado, la pérdida de tierras, detrimento cultural, la expropiación de derechos y patrimonio de las comunidades rurales que viven en zonas de interés extractivo. Es importante mencionar la gran ventaja que se evidencia han alcanzado las estructuras criminales en el marco del "boom minero" y la debilidad institucional del gobierno para afrontar esta serie de problemáticas que se han venido evidenciado tras la penetración de la minería en la nación.

Palabras Claves: territorio rural, minería, conflicto armado, población rural, minería ilegal.

\footnotetext{
* Administradora en salud: énfasis en gestión sanitaria y ambiental/especialista en Salud Ocupacional/Magíster en Epidemiología (Universidad de Antioquia). Postulante a doctorado en desarrollo sostenible (Universidad de Manizales), Colombia. Afiliación institucional: docente Facultad Nacional de Salud Pública Universidad de Antioquia. Coordinadora de la línea de investigación de epidemiología ambiental y ocupacional del grupo de investigación en salud y ambiente. Colombia. Correo electrónico: margarita.perez@udea.edu.co

** Administradora en salud: énfasis en gestión sanitaria y ambiental, Colombia. Afiliación institucional: egresada Facultad Nacional de Salud Pública Universidad de Antioquia. Perteneciente a la línea de investigación de epidemiología ambiental y ocupacional del grupo de investigación en salud y ambiente y a la línea de salud sexual y reproductiva. Colombia. Correo electrónico: anibetancur@hotmail.com
} 


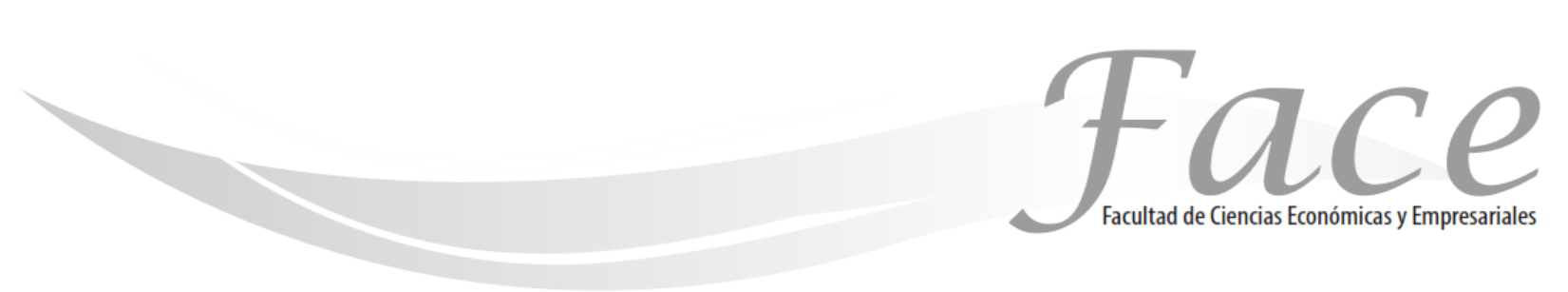

RURAL MINING IN COLOMBIA: THE PARADISE OF LEGALITY AND ILLEGALITY

\begin{abstract}
:
The expansion of the mining industry in Colombia, has been carried out within the framework of their rural environments, which are highly conducive to the execution of such work because of their characteristics in terms of detachment from civil society and the natural wealth, status which has triggered a series of changes in terms of social, cultural and territorial dynamism of such areas due to changes "imposed" in most cases not only by the State through titling mining areas, but also from armed outlaw actors, who in turn, have seen this activity profitable and beneficial option in terms of revenue collection for their support. This document aims to link the incursion of the mining industry with the expansion of the armed outlaw groups in rural areas; It is obtained through a literature review, analytical and thoughtful character. With the main result forced displacement, loss of land, cultural detriment, the expropriation of rights and heritage of rural communities living in areas of interest extractives. It is important to mention the great advantage that evidence have reached criminal structures under the "mining boom" and institutional weakness of the government to address this series of problems that have been shown after penetration of mining in the nation.
\end{abstract}

Keywords: Rural territory, mining, armed conflict, rural population, illegal mining.

\title{
MINERAÇÃO RURAL NA COLÔMBIA: A LEGALIDADE EA ILEGALIDADE PARADISE
}

\section{Resumo:}

A expansão da indústria de mineração na Colômbia, foi levada a cabo no âmbito dos seus ambientes rurais, que são altamente propício para a execução de tais trabalhos devido às suas características em termos de descolamento da sociedade civil e da riqueza natural, o estado que tem desencadeou uma série de mudanças em termos de dinamismo social, cultural e territorial dessas áreas devido a mudanças "imposta" na maioria dos casos, não só pelo Estado através de áreas de mineração de titulação, mas também de atores fora da lei armados, que, por sua vez, já vi isso atividade opção rentável e benéfico em termos de arrecadação de receitas para o seu apoio. Este documento visa interligar a incursão da indústria de mineração com a expansão dos grupos fora da lei armados nas zonas rurais; É obtido através de uma revisão da literatura, caráter analítico e pensativo. Com o deslocamento principal resultado forçado, perda de terra, em detrimento cultural, a expropriação de direitos e patrimônio das comunidades rurais que vivem em áreas de extrativos de juros. É importante mencionar a grande vantagem que as evidências atingiram estruturas criminosas no âmbito do "boom da mineração" e fraqueza institucional do governo para lidar com esta série de problemas que têm sido mostrados após a penetração da mineração no país.

Palavras-Chave: território rural, mineração, os conflitos armados, a população rural, mineração ilegal. 
Margarita María Pérez Osorno - Angie Betancur Vargas

\section{INTRODUCCIÓN:}

La denominada "locomotora de desarrollo" colombiana, en los últimos mandatos de los presidentes Uribe y Santos ha sido caracterizada por la incursión en el país del señalado "boom minero energético", industria que ha marcado fuertemente los últimos Planes de Desarrollo Nacional, los cuales han fomentado la reconocida expresión "Prosperidad para todos"; el apoyo del Estado al sector extractivo es tan elevado que se evidencia en el número de concesiones y titulaciones mineras: según Gonzáles (2015), de las 114'218.901,09 hectáreas que cuenta Colombia, 5'084.084,91 han sido otorgadas para su explotación mineral:

"En números de la Agencia Nacional de Minería (ANM), existen 9.594 títulos mineros vigentes, correspondientes al $4,5 \%$ del territorio nacional, y de ellos, 3.557 están en exploración, 2.273 en construcción y montaje, y 3.764 en explotación" (Gonzáles, 2015).

El problema actual de Colombia, en materia extractiva, radica en que su potencial es tan elevado, que no solo se evidencia en la cantidad de áreas licitadas por orden del gobierno para este fin, sino también en el incremento de manera paralela de las cifras de minería ilegal, la cual ha sido ejecutada en la gran mayoría de los casos por los grupos armados al margen de la ley con el fin de financiar sus actividades y organizaciones. Ambos contextos de legalidad e ilegalidad del sector, han generado el aumento de los conflictos internos del país escenario que ha sido manifiesto por un número incontable de muertes, destrucción y despojo de territorios.

Colompbia (2011) en uno de sus informes titulado "Minería en Colombia ¿A qué precio?", cita a Clavijo Martin J. con el argumento de que analizando el mapa minero colombiano, se puede observar que este coincide con la ubicación de ciertos actores armados ilegales y argumenta que este tipo de zonas representan la mayor cantidad de violación a los derechos humanos:

“(...) De hecho, el $80 \%$ de las violaciones de los derechos humanos que ocurrieron en Colombia en los últimos diez años se produjeron en regiones minero-energéticas y el $87 \%$ de las personas desplazadas proceden de estos lugares" (Colompbia, 2011).

Este escenario es más alarmante cuando se tiene en cuenta el tipo de entornos en los que se lleva a cabo esta labor, los cuales son marcados por unas características altamente rurales, y representan el hábitat de gran parte de las comunidades campesinas, indígenas y afrodescendientes de la nación; colectividades que según el Ministerio de Salud (s.f.), por sus características económicas, institucionales, sociales y culturales representan las denominadas "poblaciones vulnerables", situación que evidencia que las áreas mineras colombianas representan una triple condición de riesgo: el estado de vulnerabilidad social de sus habitantes, el conflicto territorial por la incursión de esta labor mediante la titulación de tierras y el interés extractivo de las organizaciones criminales, quienes ven en estas zonas, "paraísos" para su supervivencia, dado que poseen las condiciones propicias para esto: en primera estancia, olvido de la mano del gobierno, por ende no hay control y vigilancia publica y en segunda medida, tierras ricas y prósperas que generan un sin número de beneficios para cualquier tipo de industria.

La realidad es muy simple, el desarrollo del sector minero no se puede dar en zonas destinadas al dominio urbano debido a la infraestructura, estilos de vida y a que este tipo de medios no propician las condiciones aptas para llevar a cabo de manera eficiente esta labor, si bien, existen algunas concesiones mineras dentro de ciudades colombianas, estas, son muy limitadas, las áreas geográficas favorecedoras para esta actividad representan las denominadas zonas baldías, territorios étnicos y el campo, donde se encuentran los minerales de gran interés, entornos ricos a nivel medio ambiental (debido a la escasa influencia del desarrollo urbano), gran cantidad de biodiversidad, recursos y espacios "olvidados" para el desarrollo civil de parte del gobierno, pero que han dejado de pasar del abandono, para convertirse en zonas de interés minero energético, no solamente para el Estado, sino también para los grupos subversivos; cabe destacar que cuando se habla de "pasar del abandono", se hace referencia únicamente a las áreas geográficas como tal, las poblaciones, por el contrario, han sido mucho más relegadas, pues pasaron de ser colectividades aisladas del dominio público, a ser comunidades desplazadas por la violencia generada tras el desarrollo de este tipo de actividad, no solo de manera ilegal sino también legal, considerando que la explotación minera, genera un sin número de desplazamientos forzados bien sea de manera indirecta o directa: las repercusiones generadas por la minería, minimizan las capacidades de supervivencia en el contexto donde se lleve a cabo, a causa de la limitación de recursos que se produce.

En el marco de este documento, al hablar de territorios impactados por el conflicto armado a causa del desarrollo minero energético, necesariamente se habla de población rural; el presente artículo, tiene como objetivo relacionar la incursión de la industria minera con la expansión de los grupos armados al margen de la ley en territorios rurales; pretendiéndose con esto, identificar el contexto actual del país en materia de conflicto armado y desarrollo minero en este tipo de poblaciones, reconocer las poblaciones rurales 
afectadas por este fenómeno y evidenciar algunos mecanismos de apropiación empleados por este tipo de organizaciones criminales para su sostenimiento en base a este sector industrial; lográndose a través de una revisión literaria de carácter reflexivo y analítico.

\section{MARCO TEÓRICO:}

En el presente apartado se pretende identificar el contexto actual del país en materia de conflicto armado y desarrollo minero en este tipo de poblaciones, reconocer las poblaciones rurales afectadas por este fenómeno y evidenciar algunos mecanismos de apropiación empleados por este tipo de organizaciones criminales para su sostenimiento en base a este sector industrial, y para esto se consultaron fuentes de comunicaciones como: la Agencia de Noticias Universidad Nacional, el Diario del Sur, El Pueblo, El tiempo y Revista semana, a su vez, se estudiaron investigaciones realizadas por autores como: Chaparro y Pérez, Sergio Gonzáles, Leonardo Gonzáles, Güiza, Ibáñez y Laverde, Juárez Mejía e informes de organizaciones como: Cit Pax Colombia y observatorio internacional DDR-ley de justicia y paz, Colompbia, Corporación Nuevo Arco Iris y Fundación Avina Colombia, Defensoría Delegada para los Derechos Colectivos y del Ambiente, Human Rights Everywhere, Ministerio de salud, Red por la justicia ambiental en Colombia.

En Colombia, los territorios que representan mayor número de violencia y desigualdad social, son aquellos relacionados con las áreas rurales, allí, hoy en día, se presenta una serie de conflictos basados en el uso y propiedad de las tierras, no solo por parte del Estado, sino también de los grupos al margen de la ley, quienes ven en estos territorios una posibilidad de adquirir ganancias y mecanismos para su manutención y sostenimiento, debido a su lejanía de la población civil y organismos de control.

"Durante más de cuatro décadas el campo ha sido escenario de violencia, pobreza y reformas fallidas 0 inconclusas. El 94 por ciento del territorio del país es rural y el 32 por ciento de la población vive allí. Hay múltiples conflictos relacionados con el uso y la tenencia de la tierra, y una deuda social enorme (...)" (Revista semana, 2012).

Según Revista Semana, (2011), el periodista Simón Romero del periódico New York Times, en un recorrido realizado a varias minas del departamento antioqueño, percibió la realidad en cuanto a la influencia de la extracción del oro de manera ilegal para el financiamiento del conflicto armado del país, en dicho reportaje el periodista manifestó como el auge del precio del oro ha generado una nueva fuente de ingresos de organizaciones al margen de la ley como las FARC y diversas bandas criminales.

Actualmente, una de las problemáticas más relacionadas con los conflictos sociales rurales, se encuentra asociada al desarrollo de la expansión minera, debido al auge que este ha simbolizado para la economía del país, lo cual, ha originado un alto número de desplazamiento y violencia civil a causa de la tenencia de los territorios y modo de uso y productividad de estos, no solo de parte del Estado, sino también de ciertas organizaciones criminales, quienes han visto en esta, una actividad menos riesgosa para sus ingresos (situación contraria que se presenta con el narcotráfico o cultivos ilícitos), lo cual ha propiciado un interés enorme de parte de este tipo de grupos por la "posesión" del mayor número de hectáreas rurales que les sea posible para así poder adquirir mayor capital, y como consecuencia, se ha forjado la exterminación y sumisión de todo lo que impida su objetivo de dominio y enriquecimiento.

En el reporte realizado por Numa (2014) sobre un informe publicado por la contraloría el 16 de enero de 2014, se argumenta que es inmutable la aparición de grupos al margen de la ley en las principales zonas mineras del país, situación evidenciada en el mismo documento, en el cual se pone en evidencia que la minería ilegal, podría lavar por año cerca de 10.000 billones de pesos, siendo esto uno de los resultados de la imposibilidad de los organismos de control y vigilancia de ejercer adecuadamente sus funciones: $37 \%$ de las 14.357 unidades mineras registradas entre los años 2010 y 2011 poseían título minero y un $65 \%$ no pagaban regalías.

"La minería ilegal ha sido la actividad para el lavado de dinero más fácil y rentable en la historia del narcoparamilitarismo colombiano. Pues con solo tener el dinero para comprar oro en Europa oriental o África y traerlo a Colombia vía Panamá para luego venderlo al Banco de la República como si lo acabaran de extraer de una mina de Remedios - Antioquia lo convierte en un gran empresario del oro" (Gonzáles, s.f.).

"La minería en Colombia que reporta el $2.4 \%$ del total de nuestra economía se encuentra en una encrucijada: por su desorganización y la continua persecución del gobierno a los artesanales, ha dado pie para que sector tan importante de nuestra economía esté camino a convertirse en un paraíso de lavado de activos. Esto podría suceder ya que el $25 \%$ del capital de este delito es proveniente de la minería, según investigaciones reveladas por fuentes oficiales". (Ortiz, 2014). 
Margarita María Pérez Osorno - Angie Betancur Vargas

La situación actual que viven las poblaciones rurales de Colombia presentan una doble condición de riesgo: tanto el Estado como los grupos armados al margen de la ley desean adueñarse de sus dominios, es decir: por cualquier lado que miren su contexto en cuanto a posición de sus territorios hay dos gigantes que los desean y bien sea a nivel legal (titulación de zonas mineras) o ilegal (usufructo de grupos armados de sus áreas geográficas), estos tienen todas las de perder en la gran mayoría de los casos.

A continuación, se dará a conocer el contexto actual en materia de conflicto armado que padecen este tipo de territorios, por ser áreas de gran interés en materia minero energética.

\subsection{Contexto actual del país en materia de conflicto armado y desarrollo minero energético en poblaciones rurales}

Como se ha podido evidenciar, tras el aumento de las materias primas en Colombia, los grupos armados ilegales, comenzaron a volcar su mirada en la industria minera, lo que ocasionó la incursión de estos en la minería ilegal bien sea por medio de presión a mineros artesanales o de manera directa a través de la explotación a mediana escala:

"Las FARC es el grupo armado ilegal que más influencia ejerce en este sector, con presencia en departamentos como Antioquia, Bolívar, Caquetá, Casanare, Cauca, Chocó, Nariño y Tolima (...) Le sigue el ELN, con presencia en el Sur de Bolívar, Chocó, Nariño y Santander, seguido muy de cerca por las llamadas Bandas criminales (BACRIM), que están cada vez más involucradas en estas actividades principalmente en Antioquia, Sur de Córdoba, Cauca, Valle y Nariño" (Cit Pax Colombia y Observatorio Internacional DDR-ley de justicia y paz , 2012).

Con respecto a lo anterior, autores como Mejía (2012), manifiesta que la tasa de violencia entre municipios productores de oro y los que no tienen como medio de producción este tipo de industria, representan mayores tasas de violencia, siendo importante tener presente que esta variable tiene mucha relación con la explotación ilegal de dicho mineral.

"Como sabemos, las organizaciones ilegales se adaptan rápidamente y escogen asignar su capital a las actividades más rentables en donde puedan tener una ventaja comparativa, que sumada a una amplia disponibilidad de mano de obra, ha llevado a un auge sin precedentes en la explotación ilegal de oro en Colombia en los años recientes. Pero, desafortunadamente, con el auge reciente de la explotación ilegal de oro ha venido también un aumento significativo en los niveles de violencia, el cual ha sido particularmente notorio en aquellos municipios en donde, por razones geográficas (municipios cercanos a zonas volcánicas, con presencia de ríos, etc.), hay presencia de oro". (Mejía 2012).

Como se pudo demostrar, el desarrollo extractivo minero, no solo ha presentado una ventana que airea la economía de la nación por parte de las ganancias Estatales, sino también a organizaciones criminales como las FARC, ELN, y las BACRIM, quienes ejecutan esta actividad a través de medios ilegales, lo cual, está altamente relacionado con altos índices de violencia y criminalidad, que pone en riesgo la vida de las comunidades que habitan en "áreas de interés" para este tipo de grupos, la situación es mucho más preocupante en estos casos debido a que estas organizaciones no miden sus límites y ejecutan cualquier tipo de acciones para expropiar a las poblaciones de estas zonas, tales como intimidaciones, masacres, desplazamientos forzados y demás casos de violencia civil existentes.

\subsection{Poblaciones rurales afectadas por la incursión minera e interés de los grupos al margen de la ley}

Según Human Rights Everywhere (2012), el Estado colombiano da razón a la evidencia actual que han demostrado algunos medios de comunicación, en cuanto a que este no posee la capacidad necesaria para promover mecanismos de control y vigilancia en lo referente al sector minero, no solo a las grandes empresas, sino también de parte de las organizaciones criminales, quienes emplean esta actividad con la finalidad de lavar activos del narcotráfico y financiar sus arcas (dicho anteriormente), a continuación, se dará a conocer los impactos generados a algunas comunidades tras esta falla gubernamental, lo cual ha originado la propulsión y un ciclo repetitivo de violencia y dominio de las organizaciones criminales en las áreas mineras rurales del país.

Un estudio realizado por Ibáñez y Laverde, (s.f.), en el cual se pretendía contextualizar la situación actual de los municipios mineros en Colombia, pone en evidencia el tema central del objeto de estudio en este artículo:

"En los municipios de oro y plata la presencia institucional es bastante débil y la incidencia del conflicto, medida como la victimización de la población civil, es mucho mayor. Los municipios de oro y plata tienen mayores tasas de homicidios, indicadores de desplazamiento forzado y área sembrada de coca frente a los no mineros. Por el contrario, los de carbón tienen cifras menores en esta categoría frente a todos 
los demás grupos de municipios (...)" (Ibáñez y Laverde, s.f.).

Lo anterior, deja entrever, que la incidencia de conflicto armado en zonas destinadas a explotación minera se concibe tras la carencia de instituciones de orden público, situación favorecedora para las organizaciones criminales, pues, pueden ejercer con mayor autonomía y libertad su control y dominio sobre este tipo de territorios, también se evidencia que los resultados más predominantes ante esta situación, son los altos índices de desplazamiento y muertes de los pobladores de estas zonas, lo que genera un ciclo repetitivo de esta problemática, debido a que el Estado aun conociendo este contexto de violencia que padecen las poblaciones rurales de carácter minero a causa de los grupos armados, solo demuestra una presencia casi que parcial, dado que las cifras y los casos de violencia y desplazamiento de este tipo no disminuyen.

Con respecto a la minería y al conflicto armado en Colombia, El pueblo (2012) manifiesta que dentro de las poblaciones más afectadas del país, se encuentran las colectividades étnicas de la Costa Pacífica, específicamente Buenaventura, quienes han sido en gran parte desterradas de sus territorios producto de la minería ilegal y otorgación de títulos a diversas multinacionales:

"Las cifras son contundentes, de 4'311.757 afros que informa el DANE, tiene Colombia, 286.835 fueron desplazados entre 1997 y 2009, lo que equivale al $8,4 \%$ del total de población nacional, pero no es solo eso, cerca de 162 títulos colectivos de tierras también fueron entregados a comunidades afro entre 1996 y 2007, que al parecer han ido perdiendo sus dueños por las situaciones del conflicto armado interno, que genera desplazamiento" (El pueblo, 2012).

Con respecto a la acción administrativa, judicial y ejecutiva del gobierno, Güiza (2011), argumenta en uno de sus artículos investigativos que el avance que ha tenido Colombia en cuanto a la legislación minera y ambiental, ha sido inspirado en los sistemas anglosajones, situación que propició la generación de un avance en cuanto al marco normativo con un desconocimiento profundo del contexto nacional, y cuya consecuencia principal, ha sido el quebrantamiento e incumplimiento de los estatutos: en el país, aproximadamente el $30 \%$ de las explotaciones de minerales no cumplen con los debidos permisos y concesiones, lo que a su vez fomenta la ilegalidad de esta actividad.

Como se puede probar, la presencia de un marco regulador, no garantiza un adecuado cumplimiento de sus normas, y mucho menos, si se carece de un organismo de control y vigilancia que lo garantice, no se puede estipular un conjunto de legislación minera y ambiental en el contexto colombiano, si se toman como base modelos externos, puesto que las dinámicas sociales y territoriales del país son únicas y representan sus propios conflictos y divergencias.

Otro caso objeto de estudio en una de las investigaciones consultadas, el cual demuestra las consecuencias del olvido del gobierno en algunas poblaciones y la insurgencia de los grupos armados ilegales, fue el municipio de Suarez, Cauca, el cual, se caracteriza por poseer una minería de oro pequeña y artesanal, desde la época colonial; a nivel general el estudio realizado por Corporación Nuevo Arco Iris y Fundación Avina Colombia (2012), titulado "Violencia colectiva y minería en Colombia: hallazgos preliminares a partir de dos estudios de caso", puede constatar una dinámica social marcada por la violencia propulsada por diversos grupos armados al margen de la ley los cuales combaten constantemente por el dominio de las áreas denominadas de explotación y exploración minera:

"Suárez se caracteriza por tener una ubicación de difícil acceso para las Fuerzas Armadas por el mal estado de sus vías terrestres. Esas mismas condiciones han facilitado la acción de guerrillas y paramilitares. De igual forma, la ubicación geográfica del departamento (proximidad al Océano Pacífico y a países fronterizos como Ecuador y Perú) incidió en el incremento del narcotráfico, debido a que esta región se constituyó en un corredor que le permite a las FARC-EP llevar a cabo incursiones armadas hacia los territorios vecinos, traficar armas, ingresar a sus campamentos alimentos $e$ insumos para el procesamiento de cocaína y heroína, así como sacar pasta de coca y marihuana, su principal fuente de financiación" (Corporación Nuevo Arco Iris y Fundación Avina Colombia, 2012)

Según una entrevista realizada al representante de la Asociación indígena y campesina del Gran Jardín de la Sierra, del departamento de Nariño, Julián Otero, en el marco del Cuarto Encuentro Internacional de Culturas Andinas por Diario del Sur (2014), el conflicto armado sumado a la explotación minera que se ha llevado a cabo en sus territorios, han originado el desplazamiento de más de 2000 indígenas del piedemonte costero y el sur del departamento de Nariño, esto se suma a la perdida cultural de sus etnias, asesinatos, contaminación de las fuentes hídricas y robos de propiedades.

Todos los casos nombrados anteriormente presentan las mismas características: la mayoría de los contextos 
Margarita María Pérez Osorno - Angie Betancur Vargas

ostentan territorios aislados de la sociedad civil, con insuficiencia institucional por parte del Estado, a su vez, debilidad en cuanto a procesos tanto sociales como políticos y económicos, inadecuado manejo y escasez a nivel de infraestructura no solo vial, sino también civil, y fuera de esto las repercusiones ambientales adyacentes al desarrollo de la minería ilegal que llevan a cabo este tipo de organizaciones carecen de cualquier acatamiento en cuanto a normatividad ambiental y social.

Las características violentas de este tipo de organizaciones al margen de la ley, genera un mayor riesgo para las comunidades rurales que se desenvuelven en áreas de interés minero, dado que estas se ven ceñidas a tener que desplazarse bien sea de manera "voluntaria" o por la misma presión de estos grupos, fuera de esto, deben presenciar altos índices de hostigamientos, hurtos, despojos, muertes y demás tipo de violencia física y psicológica que estas organizaciones ejercen.

Otro asunto importante a estudiar es el cómo las empresas se benefician tras la violencia ejercida por los actores ilegales a las comunidades. Con respecto a esto, el portal "Red por la justicia ambiental en Colombia" (2014), señala en uno de sus reportes este tipo de casos, dado en el Cesar, tras la explotación minera del Carbón que realiza en este territorio las concesiones de Drummond y Prodeco:

"Varios testimonios, tanto de las víctimas como de los autores, indican que las empresas mineras se han beneficiado de varias maneras de los abusos de los derechos humanos cometidos por las AUC y que lo continúan haciendo hasta el día de hoy. En primer lugar, al menos tres casos de desplazamiento forzado tuvieron lugar en tierras que actualmente están situadas en las concesiones de Drummond y Prodeco o cerca de ellas. En segundo lugar, el asesinato de los líderes sindicales mineros y las continuas amenazas contra las vidas de otros miembros han debilitado los sindicatos en la región y les permiten a las empresas abstenerse de mejorar la seguridad y las condiciones laborales de los empleados de las empresas. Y por último, la violencia ha silenciado las voces críticas de las comunidades locales y de las organizaciones de la sociedad civil en los temas de derechos humanos y los impactos sociales y ambientales de la minería del carbón". (Red por la justicia ambiental en Colombia, 2014).

Debido a todo lo visto en el marco de esta categoría, se hace imprescindible, establecer cuál es el "modus operandi" de los grupos al margen de la ley en este tipo de territorios, generando así, una mayor claridad de la problemática que vivencian las comunidades rurales de zonas mineras colombianas.

\subsection{Mecanismos de apropiación empleados por las organizaciones criminales para su sostenimiento en base a la industria minera}

Según la Defensoría Delegada para los Derechos Colectivos y del Ambiente (2010), en el caso colombiano, la minería aurífera, ha representado una de las principales fuentes para el lavado de dinero proveniente del narcotráfico, empleando como principales mecanismos los siguientes métodos: Compra de producción a los mineros locales e importación de oro de contrabando derivado de países vecinos, con el propósito de hacerlos pasar como fabricación de minas fachadas y adquisición de maquinaria obtenida con dólares provenientes del narcotráfico, a su vez, los grupos al margen de la ley emplean como medio de financiación la extorción a mineros de hecho y tradicionales por medio de la solicitud de pagos periódicos.

Lo anterior, no dista mucho de lo descrito en el informe ejecutado por Cit Pax Colombia y el Observatorio Internacional DDR-ley de justicia y paz (2012), en el cual, se señala, que en la actualidad existen diversos mecanismos empleados por estos tipos de grupos para llevar a cabo su sostenimiento con la actividad minera, entre ellos se encuentran: la intervención de estos grupos de manera directa por medio de la gestión de producción extractiva a nivel local, y la mediación de manera indirecta por medio de la prestación de servicios y empleo de intermediarios.

Intervención directa:

a. Aprovechamiento directo: en este caso, estas organizaciones, son poseedoras y dueñas de la maquinaria, y abren sus propias minas con el fin de evitar que otra persona opere en el sector que estos han designado como "propio". Generalmente, se adueñan de zonas al margen de la ley y apartadas de la sociedad civil.

b. Creación de empresas fachada: en este caso, por medio de nombres falsos, dichas estructuras criminales adquieren de manera "legal" la concesión de títulos mineros en diversos territorios.

c. "Robo de combustibles y refinerías de crudo ilegales": en algunos casos, no solo participan como gestores en el procesamiento del crudo, sino también en el robo de este; esto lo llevan a cabo por medio de cobro de cuotas a terceros 0 por medio de la refinanciación de crudo hurtado a diversas empresas petroleras.

Mediación indirecta: 
a. Grupos delictivos como propulsores de protección: este prototipo de soborno es empleado por medio de cobro de cuotas extorsivas a mineros artesanales, pequeños mineros y a empresas multinacionales.

b. Organizaciones criminales y sus alianzas con multinacionales: Estos grupos, proporcionan bien sea de manera directa, 0 indirecta la afluencia de multinacionales por medio del "despeje" de las zonas de interés, esto lo hacen a través de provocaciones, intimidaciones, asesinatos y desplazamientos.

Lo anterior, deja notar el sistema interno que emplean estas estructuras criminales para tener un dominio absoluto, pudiéndose estimar que no solo ejercen un control sobre las comunidades como tal, sino también sobre las multinacionales apoyadas por el gobierno, situación que es mucho más preocupante, considerando que en el primer caso, como se evidenció en la categoría anterior estas colectividades no cuentan con un apoyo institucional pertinente por diversas razones (nombradas en dicha categoría), lo que sin embargo no justifica al Estado, pero en el segundo caso, hay un apoyo gubernamental abierto y decidido, por medio de "contratos" y concesiones.

\section{METODOLOGÍA:}

Para relacionar la incursión de la industria minera y su correlación con la expansión de los grupos armados al margen de la ley en territorios rurales, y los mecanismos, métodos y acciones que este tipo de grupos emplean para "apoderarse" de los territorios que "eligen" como zonas de interés; se consultaron diversas fuentes bibliográficas que abordaban la temática objeto de estudio: boletines informativos, libros, artículos de investigación y documentos electrónicos, los cuales fueron respectivamente sistematizados y analizados.

\subsection{Estrategias metodológicas}

Esta investigación, se elaboró a través de dos fases: la primera de énfasis informativo, en la cual se consultó y eligió la información referente al tema objeto de estudio y la segunda de carácter analítico y reflexivo, en la cual se comprobó y validó la información obtenida en la primera fase.

\subsection{Procedimiento}

En la fase informativa se realizó, la indagación de bases de datos bibliográficas encargadas de divulgar la producción científica en todas las áreas del conocimiento.
En la segunda fase, se instauraron tres categorías de investigación, utilizadas para la adaptación de la información obtenida, su análisis y reflexión, dichas categorías fueron las siguientes: Contexto actual del país en materia de conflicto armado y desarrollo minero energético en poblaciones rurales, poblaciones rurales afectadas por la incursión minera e interés de los grupos al margen de la ley y mecanismos de apropiación empleados por las organizaciones criminales para su sostenimiento en base a la industria minera. Los programas empleados para la recopilación, organización, análisis e interpretación de los resultados fueron word y excel.

\section{DISCUSIÓN:}

¿Qué tanta influencia tienen las organizaciones criminales en el desarrollo social, político y económico del país?, ¿Cuál ha sido el papel del gobierno como regulador e impulsor de este tipo de industria a nivel nacional? En este apartado, se pretende proporcionar una reflexión en cuanto a este tipo de interrogantes y evidenciar el contexto actual del país en materia de minería ilegal y sector rural.

"Los profesores e investigadores de la Facultad de Ciencias Económicas William Chavarro y Milton Pérez, centraron sus intervenciones en el actual modelo económico del campo en el país, que según ellos, está basado en un desarrollo rural sin base social, sin territorio ni campesinos que busca abrir cada vez más espacio para los grandes proyectos industriales y mineros" (Chavarro y Pérez, 2014).

En la actualidad el gremio social más afectado por el desarrollo de la producción minero energética es el rural, infortunadamente, como se pudo apreciar a lo largo del documento, son estas zonas las que presentan mayor riqueza en materia de biodiversidad y minerales preciosos en sus territorios, y a su vez, los más altos índices de vulnerabilidad social, teniendo en cuenta que sus tierras son altamente cotizadas no solo por el Estado (quien pretende a toda costa privilegiar la minería por encima de la producción agraria, la cual ha sido el motor de avance de Colombia por décadas, y ha propiciado el sustento de miles de nacionales), sino también por los grupos armados al margen de la ley, quienes se han aprovechado de la carencia institucional y gubernamental de estos tipos de áreas para ejercer actividades ilícitas y control sobre estas comunidades. Permitiendo pues, esta situación, dilucidar, el contexto de vulnerabilidad social, política, territorial, cultural y económica que viven las colectividades rurales 
Margarita María Pérez Osorno - Angie Betancur Vargas

de la nación, dado que sus territorios son foco del motor atroz de la industria minera, bien sea a nivel legal o ilegal.

Con base a lo anterior, se genera pues, una pregunta ¿Qué tipo de minera genera más afectaciones tanto ambientales como sociales?, de acuerdo con la Agencia de Noticias Universidad Nacional (2012), Gonzalo Andrade, docente del Instituto de Ciencias Naturales de dicha institución, argumenta que el pronunciamiento del Gobierno sobre tipificar como delito la minería ilegal, no es significativo, ya que el impacto ambiental de cualquiera de las dos formas de minería es el mismo, a su vez, argumentó que las acciones de parte del Estado, del Ministerio de Ambiente y Desarrollo Sostenible y las Corporaciones Autónomas Regionales han sido invisibles y poco contundentes.

A lo anterior, es importante tener presente que si bien se han implementado ciertas acciones de parte del gobierno para minimizar la acción de los grupos armados ilegales, también se hace importante reiterar que estas han sido mínimas si se comparan los resultados obtenidos por parte del Estado con los de estas organizaciones:

Según Juárez (2015), en el Primer Congreso de Minería llegal, llevado a cabo en Bogotá en el año 2011, la Policía Nacional señaló que en Colombia para ese año, se habían cerrado 275 minas, se ejecutaron 1.228 arrestos y se inmovilizaron cerca de 125 máquinas en aproximadamente 27 de los 32 departamentos del país. Contrarrestando estas cifras, la Revista semana (2013), en uno de sus artículos informativos, expresa que según datos de la Policía nacional, del total de municipios del país que llevan a cabo la extracción de minerales, 151 de 25 departamentos ejecutan esta labor de manera ilegal y con una alta presencia de los grupos delictivos, a su vez, manifiesta que en un estudio reciente realizado por la Fundación Ideas para la Paz, se evidencia que en más de la mitad de los municipios productores de oro, prevalecen organizaciones criminales; en este mismo reportaje, semana enuncia que si bien no se tienen cifras precisas de las ganancias que generan los grupos delictivos a través de la extracción de minerales, se cuenta con una aproximación somera: de 51 toneladas que el país exportó en el año 2012 por 2.311 millones de dólares, más de la mitad provenía de la minería informal.

Estas cifras demuestran el nivel de poder que tienen estas organizaciones sobre el desarrollo de este sector económico en la nación, teniendo en cuenta que generan mayor cantidad de ingresos que la minería concedida y permitida por el Estado a través de títulos a multinacionales, a raíz de esto surge un interrogante ¿Quiénes son los verdaderos beneficiados con el auge de este tipo de industria en Colombia?, porque si bien, la extracción minera genera cierto ingreso en las arcas económicas del gobierno, estos grupos, también ven en el desarrollo de esta actividad una alternativa eficaz y contundente para subsanar sus necesidades y permitir entradas monetarias para sus líderes y enriquecimiento interno.

Lamentablemente, a nivel institucional y de normatividad, el Estado colombiano cuenta con ciertas falencias y debilidades que como se puede apreciar generan solo ganancias para este tipo de organizaciones, mientras se aprovechan de territorios apartados del dominio gubernamental y que solo son tenidos en cuenta por estos para la expedición de títulos y no para su protección, control y vigilancia.

\section{CONCLUSIONES:}

Como se pudo demostrar, la implementación en el país del modelo extractivista actual, ha crecido paralelamente al poder de los actores armados, debido a la facilidad que promete este sector para el lavado de dinero y a la debilidad institucional de parte del Estado para garantizar acciones de vigilancia y control en este tipo de territorios, contexto que se puede evidenciar en la gran mayoría de las zonas mineras de Colombia, las cuales cuentan no solo con titulaciones mineras a cargo de las multinacionales, sino también con la presencia de grupos delictivos que desean la posesión de sus tierras.

Las colectividades rurales afectadas a causa del desarrollo de este tipo de industria, se pueden patentizar en las comunidades indígenas, afrodescendientes y campesinos de Antioquia, Bolívar, Caquetá, Casanare, Cauca, Chocó, Nariño, Tolima, Sur de Córdoba y Valle, quienes padecen graves consecuencias sociales y territoriales a causa del oro y carbón que poseen sus suelos y anhelan tanto el sector empresarial como subversivo del país.

Acciones como desplazamientos forzados, amenazas, muertes, intimidaciones y posesión ilegal de tierras, son algunos de los medios que este tipo de organizaciones han implementado con el fin de obtener sus beneficios; se hace pues, un llamado de atención al Estado, con el fin de recordar que Colombia también es rural y no solo las metrópolis principales de la nación, dado que las primeras consecuencias de su olvido y centralización se han visto ejemplarizadas en los índices de desigualdad social, económica, vulnerabilidad de derechos, desplazamiento y violencia que vivencian este tipo de comunidades. 


\section{REFERENCIAS:}

Agencia de Noticias Universidad Nacional (2012). El impacto ambiental de la minería legal o ilegal es el mismo. Recuperado de: http://agenciadenoticias.unal.edu.co/det alle/article/el-impacto-ambiental-de-lamineria-legal-o-ilegal-es-el-mismo.html

Chavarro, W y Pérez, M. (2014). Los impactos de las extracciones mineras en el desarrollo rural en Colombia. Comunicaciones CID. Sesión de catedra: Territorialidad, territorio y megaproyectos rurales. Ponencia llevada a cabo en Universidad Nacional de Colombia, sede Bogotá. Recuperado de:

http://www.cid.unal.edu.co/cidnews/inde x.php/inequidad-gran-problema-de-lasalud-en-bogota/2393-los-impactos-delas-extracciones-mineras.html

Cit Pax Colombia y observatorio internacional DDR-ley de justicia y paz. (2012). Actores Armados llegales y Sector Extractivo en Colombia (V). Recuperado de: http://www.askonline.ch/fileadmin/user_ upload/documents/Thema_Wirtschaft_u nd_Menschenrechte/Bergbau_Rohstoff/ Gold/Actores_armados_ilegales_sector _extractivo.pdf

Colompbia. (2011). Minería en Colombia ¿A qué precio?. PBI Colombia. Boletín informativo $\mathrm{N}^{0} 18$.

Corporación Nuevo Arco Iris y Fundación Avina Colombia. (2012). Violencia colectiva y minería en Colombia: hallazgos preliminares a partir de dos estudios de caso. Recuperado de: https://www.mesadedialogopermanente. org/wpcontent/uploads/2013/05/MINERIA-YVIOLENCIA-

COLECTIVA_21_08_2012.pdf

Defensoría Delegada para los Derechos Colectivos y del Ambiente. (2010). La minería de hecho en Colombia. Recuperado de: http://www2.congreso.gob.pe/sicr/cendo
cbib/con4_uibd.nsf/F11B784C597AC0F 005257A310058CA31/\$FILE/Laminer\%C3\%ADa-de-hecho-enColombia.pdf

Diario del Sur. (7 de agosto de 2014). La violencia y minería condenan a indígenas de Nariño. Recuperado de: http://diariodelsur.com.co/noticias/nacio nal/la-violencia-y-miner\%C3\%ADacondenan-ind\%C3\%ADgenas-denari\%C3\%B10-80576

El Pueblo. (2012). Minería ilegal y conflicto armado, problemas que siguen aquejando a la población afro. El pueblo, con todo el poder de la información: economía. Recuperado de http://elpueblo.com.co/mineria-ilegal-yconflicto-armado-problemas-quesiguen-aquejando-a-la-poblacion-afro/

Gonzáles, S. (2015). Los números de la minería en el país. El espectador. Recuperado de http://www.elespectador.com/noticias/ec onomia/los-numeros-de-mineria-el-paisarticulo-557084

Gonzáles, L. (s.f.). Minería y Narcoparamilitarismo. Indepaz.

Recuperado de: http://www.indepaz.org.co/wpcontent/uploads/2016/02/MINERI\%CC $\% 81 \mathrm{~A}-\mathrm{Y}-$ NARCOPARAMILITARISMO.pdf

Güiza, L. (2011). Perspectiva jurídica de los impactos ambientales sobre los recursos hídricos provocados por la minería en Colombia, Opinión Jurídica, edición especial, 123-140.

Human Rights Everywhere. (2011). Diagnóstico sobre la minería en territorios indígenas en Colombia. Recuperado de https://www.google.com.co/url?sa=t\&rct $=j \& q=\&$ esrc $=s \&$ source=web\&cd=4\&ved $=0$ ahUKEwjq18TjjfHNAhVL1B4KHWBR DvMQFggwMAM\&url=http $\% 3 A \% 2 F \% 2$ Fwww.podion.org\%2Fapc-aafiles $\% 2 F a 90$ cd6445b5e2203c85a247e 7 fa21751\%2FDiagn_sti.._1_1_.pdf\&usg =AFQjCNFy5alQnOSHRIU4QcRZFbhLa $\mathrm{U}$ -

VtA\&sig2=6n5tFoxFIYCJi600R7BPYw\& bvm=bv.126993452,d.dmo 
Ibáñez A. y Laverde M. (s.f.) Los Municipios Mineros en Colombia: características e impactos sobre el desarrollo. Unidad de Planeación Minero Energética. Recuperado de: http://www1.upme.gov.co/sites/default/fil es/forum_topic/3655/files/municipios_mi neros_colombia_caracteristicas_impact os_sobre_desarrollo.pdf

Juárez, F. (2015). La minería ilegal en Colombia: un conflicto de narrativas, Universidad San Buenaventura, 16(1), 135-146.

Mejía D. (8 de mayo de 2012). ¿El siguiente boom ilegal en Colombia? Minería ilegal y violencia [Mensaje en un blog]. Recuperado de: http://focoeconomico.org/2012/05/08/elsiguiente-boom-ilegal-en-colombiamineria-ilegal-y-violencia/

Ministerio de salud (s.f.). Poblaciones vulnerables. Recuperado de https://www.minsalud.gov.co/salud/publi ca/poblaciones-

vulnerables/Paginas/poblacionesvulnerables.aspx

Numa, S. (2014). La minería en Colombia: la maldición de los recursos naturales. El tiempo. Recuperado de: http://www.eltiempo.com/archivo/docum ento/CMS-13366835

Ortiz U. (25 de enero de 2014). ¿Qué pasa con la minería en Colombia? Revista Semana. Recuperado de: http://www.semana.com/opinion/articulo /mineria-en-colombia-opinion-de-urielortiz/371828-3

Red por la justicia ambiental en Colombia. (2014). Reporte: El lado oscuro del carbón. Violencia paramilitar en la región minera de Cesar, Colombia. Recuperado de: https://justiciaambientalcolombia.org/20 14/07/04/reporte-el-lado-oscuro-delcarbon-violencia-paramilitar-en-laregion-minera-de-cesar-colombia/

Revista semana

a. (2011). Oro, nuevo combustible para la guerra en Colombia: New York Times. Recuperado de: http://www.semana.com/nacion/articulo/ oro-nuevo-combustible-para-guerracolombia-new-york-times/236326-3

b. (2012). Así es la Colombia rural. Recuperado de:

http://www.semana.com/especiales/pilar es-tierra/asi-es-la-colombia-rural.html

c. (2013). Minería ilegal: entre el oro y el crimen. Recuperado de http://www.semana.com/nacion/articulo/ oro-crimen-mineria-ilegal/338107-3 